\title{
The World Health Organization at 7o: Challenges and Adaptation
}

\author{
Introductory Notes
}

\author{
Gian Luca Burci \\ Adjunct Professor of International Law, Graduate Institute of \\ International and Development Studies Geneva \\ Gian-luca.burci@graduateinstitute.ch
}

\section{Introduction}

The World Health Organization (WHO) came to life on 8 April 1948 with the entry into force of its Constitution, adopted in July 1946 by an international conference convened at the initiative of Brazil and China. Seventy years later, WHO is the largest UN specialized agency with about 8000 staff and 160 offices worldwide, and also the most universal after UNESCO with 194 member states. Its functions and activities during the course of its lifetime have been incredibly diverse, touching on most public health topics from disease-specific and vaccination programmes to the promotion of primary health care and coordinating the fight against anti-microbial resistance. ${ }^{1}$ Its history has sometimes felt like a roller-coaster of achievements and failures, from the successful eradication of smallpox and the adoption of a landmark treaty on tobacco control on the one hand, to the failure to effectively respond to the raging HIV-AIDS pandemic in the 1980s and 1990s as well as to the 2014-2016 Ebola virus outbreak in West Africa.

WHO is relatively understudied by international law scholars and its institutional and legal features are usually not the object of much scholarly analysis. ${ }^{2}$ The limited attention by international legal scholars for WHO is emblematic

1 A fine overview of WHO's functions and activities is Kelley Lee, The World Health Organization (WHO) (Routledge, 2009).

2 A recent exception is Jose Alvarez, The Impact of International Organizations on International Law (Brill 2017) 190-261. The sole systematic institutional overview of WHO in English is Gian Luca Burci and Claude-Henri Vignes, World Health Organization (Kluwer Law International, 2004). 
of the scarce attention for "technical" international organizations, but is also a symptom of the equally limited role that - until the late 199os - health has played in international law scholarship. It is not possible here to give justice to a complex historical development, suffice it to note that health has for a long time been perceived as a fundamentally domestic topic of a technical and social nature, with the notable exception of the international spread of infectious diseases that required international regulation. Moreover, the demands on WHO from its growing membership mostly concerned the fight against diseases and the strengthening of national health systems - all topics not requiring an international legal approach. For these and other reasons, WHO has remained on the sidelines of international law-making.

However, global health has undergone a revolution in the last thirty years, both in political as well as scholarly terms. The convergence in the 1990 of the HIV-AIDS crisis which confronted public health with human rights, ${ }^{3}$ the dominance of neo-liberal economic policies and international rules with a deep impact on the enjoyment of the right to health, and the incipient "securitization" of infectious diseases ${ }^{4}$ placing security agencies in charge of health protection, have changed deeply the perception of health as an increasingly political topic. The focus of policy and scholarly discourses has shifted from a biomedical and public health approach to the so-called "determinants of health" 5 and to the complex interactions between health and multiple international policy and legal regimes with special regard to economic law and its impact on access to medicines and the regulation of health risk factors. ${ }^{6}$ Health has been propelled in a short span of time to the center of development and foreign policy agendas, as proved by the increasingly frequent involvement of the UN General Assembly in health problems from non-communicable diseases to anti-microbial resistance. To complicate matters further, recent decades

3 Jonathan M Mann, Sofia Gruskin, Michael A Grodin and George J Annas (eds) Health and Human Rights (Routledge, 1999).

4 Simon Rushton and Jeremy Youde (eds), Routledge Handbook of Global Health Security (Routledge, 2015)

5 This expression refers to the factors outside the remit of public health authorities that however have a decisive influence on public health outcomes as well as inequalities within and between countries. These can range from income distribution, education level, women's empowerment all the way to national and international economic or environmental policies. World Health Organization, 'Closing the gap in a generation - Health equity through action on the social determinants of health', Commission on Social Determinants of Health (WHO 2008).

6 Benn McGrady, Trade and Public Health - The WTO, Tobacco, Alcohol and Diet (Cambridge University Press, 2011). 
have seen a crisis of multilateralism, or at least a rethinking of the rationale for organized international cooperation and the political and institutional mechanisms to pursue it. From a health perspective, the latter trend is in good part behind the recent proliferation of public-private partnerships and other institutional experiments that diverge from classical multilateralist doctrines. ${ }^{7}$

From a scholarly perspective, these developments have recently generated research and literature on the role of health in the design and implementation of various international policy and legal regimes. ${ }^{8}$ WHO has been one of the objects of this research agenda also because some of the political battles against the distortions brought about by neo-liberal economics have been fought within WHO in the name of equitable access to affordable medicines. However, WHO as an organization has still not been the object of much attention in this vein of scholarship at least from international legal scholars, with the possible exception of its role in international disease outbreaks.

This forum aims at partially redressing this lack of attention. It assembles a group of distinguished scholars and current or former WHO officials and looks in an eclectic manner at a selected range of issues to better understand a highly innovative and adaptive international institution at times of major political changes. While the topics retained for this forum are by necessity limited, the approaches adopted by the authors shed light both on the internal management of the organization - something unusual in academic legal journals - as well as on the need to rethink critically the theoretical perspectives required to fully appreciate the role and functions of international organizations in the current political environment. This, in turn, generates findings and considerations that can contribute to the current discourse and future research about the health and meaning of multilateralism at this juncture of the 21st century.

\section{Functions, Powers and Structure of WHO}

WHO represents the culmination of an historical process of international collaboration in the field of health, initially focused on the prevention and control of infectious diseases as the most evident international aspect of public health. The period in question, from mid-19th century until the Second World War, saw

7 Gian Luca Burci, 'Public/PrivatePartnerships in the Public HealthSector' (2009) 6(2) International Organizations Law Review 359; and Liliana Andonova, Governance Entrepreneurs (Cambridge University Press, 2017) 145 .

8 This body of scholarship is well represented by Gian Luca Burci and Brigit Toebes (eds) Research Handbook on Global Health Law (Elgar, 2018). 
both the adoption of numerous international conventions and regulations as well as the establishment of both regional and global organizations to put such collaboration on a firm institutional footing. The most notable institutions were, at the regional level, the Pan-American Sanitary Council (established in 1902, later renamed Pan-American Health Organization (PAHO) and still in existence) and at the global level the "office international d'hygienepublique" and the Health Organization of the League of Nations. ${ }^{9}$ This institutional development is characterized by the broadening of the scope of health problems requiring international collaboration and assistance as well as the setting of uniform international standards, away from an exclusive focus on infectious diseases. The evidence generated by the aforementioned international organizations through increased international collaboration on epidemiology and statistics, for example, shifted the focus of international cooperation to problems such as nutrition, sanitation, child and maternal mortality that often depend on endogenous factors rather than the importation of diseases. ${ }^{10}$ In this perspective, WHO continues this expansive trend of internationalization of health and represents a revolution in the institutionalization of health cooperation. The preamble to its constitution constitutes a visionary declaration that builds on the European tradition of social medicine in proclaiming a positive and all-encompassing notion of health as both a human right as well as a contributing factor to international peace and security.11

The powers entrusted to the organization also reflect the ambitions of its founders and a "managerial" vision of global health requiring strong and uniform rules and centralized oversight. This is reflected firstly in the breadth of WHO's mandate and functions listed in Article 2 of the Constitution, covering most public health issues but focusing in particular on WHO's role as "the directing and co-coordinating authority on international health work".12 Secondly, Chapter XIV of the Constitution establishes a strong system of oversight and accountability by requiring member states to report regularly on a broad range of topics, from national laws, regulations and statistics to "action taken and progress achieved in improving the health" of their population, to their

For a comprehensive history of the health organizations preceding WHO, see Neville Marriott Goodman, International health organizations and their work (Livingstone, 2nd ed, 1971).

10 For an insightful overview on the development of global health thinking, see Randall $\mathrm{M}$ Packard, A History of Global Health : Interventions in the Lives of Other Peoples (Johns Hopkins University Press, 2016).

11 Constitution of the World Health Organization, opened for signature 22 July 1946, 14 UNTS 185, entered into force 7 April 1948 ('WHO Constitution'). 
implementation of WHO's legal instruments. ${ }^{13}$ Even though compliance with such strict requirements has been interpreted flexibly in the course of time due to resource constraints and the difficult political cold war environment, there has always been an expectation that member states would contribute to the work of the organization through various forms of regular topical reports.

Thirdly, and most importantly for this forum, WHO was endowed with strong normative powers that reflect again a clear vision as early as 1946 of the global - rather than eminently domestic - nature of public health and of the need for uniform and centralized standards. Besides the authority to adopt international conventions and recommendations "with respect to any matter within the competence of the Organization", ${ }^{14}$ the World Health Assembly can also adopt by simple majority regulations legally binding for the whole membership in five enumerated areas. Regulations enter into force automatically for all member states after a prescribed period "except for such Members as may notify the Director-General of rejection or reservations within the period...."15 This far-reaching legislative authority distinguishes WHO from other specialized agencies and it's surprising that it hasn't attracted more scholarly attention. One of the possible reasons for this relative neglect has been WHO's reluctance to exercise such striking normative powers, which have been used only a few times. In its first 70 years, WHO has only adopted one convention namely, the 2003 WHO Framework Convention on Tobacco Control ${ }^{16}$ - and two regulations - the so-called Nomenclature Regulations ${ }^{17}$ and, perhaps more significantly for contemporary global health governance, the International Health Regulations last revised in 2005 (IHR (2005)). ${ }^{18}$ WHO's timidity in producing dedicated international rules for the pursuit of its mandate has been analyzed and criticized since the 1990s by the few (largely North American) scholars who have focused on the role of health as a normative value in international law and advocated a more active role for WHO. ${ }^{19}$ At the same time, the political and

13 Ibid, Articles 61-63.

14 Ibid, Articles 19 and 23.

15 Ibid, Articles 21-22.

16 WHO Framework Convention on Tobacco Control, opened for signature 16 June 2003, 2302 UNTS 166, entered into force 27 February 2005.

17 Nomenclature Regulations, Res WHA20.18, 160 OR 9 (22 May 1967). Burci and Vignes, above $\mathrm{n} 2,132$.

18 International Health Regulations (2005), Res WHA58.3, WHA58/2005/REC/1 7 (23 May 2005).

19 Allyn Lise Taylor, 'Making the World Health Organization Work: A Legal Framework for Universal Access to the Conditions for Health' (1992) 18 American Journal of Law and Medicine 301. 
normative significance of the few binding legal instruments adopted by WHO should not be underestimated, since they address in innovative ways two of the most challenging global health problems - the spread of emerging and reemerging infectious diseases on the one hand; and the fight against tobacco as one of the main risk factors of non-communicable diseases on the other.

The IHR (2005), in particular, constitute an ambitious experiment to address the still unsolved problem of how to protect the world from potentially devastating diseases that can arise from natural causes as much as from accidental or even deliberate release of noxious substances and pathogens. ${ }^{20}$ The IHR (2005) have replaced the old system of surveillance and response dating back to the $19^{\text {th }}$ century, based on an exhaustive list of diseases and maximum measures applicable at the border to persons, conveyances and goods, with an international coordination system and set of rules unrelated to particular diseases and based on scientific evidence, a contextual risk assessment shared between WHO and its members, and far-reaching obligations to strengthen national public health systems. This approach aims inter alia at ensuring consistency of health control measures with other bodies of international law such as those on trade and human rights, thus facilitating compliance. What matters most for the purpose of this forum is the unprecedented delegation of authority in favour of WHO's Director-General who can proclaim a "public health emergency of international concern", adopt consequential temporary recommendations, coordinate international collaboration and response and even keep information in confidence under certain conditions to reassure countries fearing disproportionate reactions. The IHR (2005) are institutionally embedded in WHO, which is not only their custodian and "manager" but also supposed to use them as a tool for its own operational activities in emergencies and to integrate them in its broader mandate (e.g. on strengthening national health systems).This integrated approach is now strengthened by the establishment by the Executive Board in 2015 - in the first exercise ever of its emergency powers during the Ebola outbreak ${ }^{21}$ - of a WHO operational emergency programme that assigns unprecedented new responsibilities to the WHO Secretariat and should dovetail with the implementation of the IHR. ${ }^{22}$

20 Seminal is David P Fidler, 'From International Sanitary Conventions to Global Health Security: The New International Health Regulations' (2005) 4(2) Chinese Journal of International Law 235 .

21 Ebola: ending the current outbreak, strengthening global preparedness and ensuring WHO's capacity to prepare for and respond to future large-scale outbreaks and emergencies with health consequences, EB Res EB/SS3/R1, EBSS/3/2015/REC/1, 2nd mtg (25January 2015) 3.

World Health Organization, 'WHO in emergencies' < https://www.who.int/emergencies/ en/> 
Another remarkable aspect of WHO is its governance, both with regard to its original constitutional structure, its adaptation in the light of developments in global health governance, as well as its engagement in innovative international structures such as public-private partnerships. ${ }^{23}$ As noted above, the historical origins of WHO led to enshrining in its Constitution an unprecedented role and space for "regional organizations", largely as a legacy of the organizations predating WHO's establishment. ${ }^{24}$ This approach to regional cooperation as part of the constitutional framework of an international organization is unique within the UN system. Coupled with the fact that regional directors (the heads of WHO's regional offices) are nominated by their respective regional committees and confirmed by the Executive Board (they are in practice selected by the states of their respective regions rather than by the Director-General or the whole membership), the centrifugal forces generated by this framework and the resulting tensions among the various parts of the organization have marked the entire history of WHO. ${ }^{25}$ Even more unique in this respect is the status of PAHO, which continues to exist as an entirely separate regional organization outside the UN system but serves at the same time as WHO's regional committee and office for the Americas by virtue of an agreement concluded between the two organizations in $1949 .{ }^{26}$ This unprecedented arrangement, under which an international organization places itself permanently at the disposal of another organization as an organ thereof while continuing to operate as a separate institution, raises delicate questions of attribution and responsibility and has generated much ambiguity in the dayto-day relations between WHO and PAHO. ${ }^{27}$

\section{The Contemporary WHO in the Contributions to the Forum: Institutional Adaptation, Analytical Tools and Lessons for Multilateralism}

The perceived weaknesses of WHO's response to the 2009-2010 HiN1 influenza pandemic and to the aforementioned Ebola outbreak have generated a

\footnotetext{
23 Burci, above $\mathrm{n} 7$.

24 WHO Constitution, Articles 44-54. For an overview, see Burci and Vignes, above n 2, 53-61.

25 Burci and Vignes, above n 2, 53; Lee, above n 1, 30.

26 Agreement between the World Health Organization and the Pan-American Health Organization, concluded 22 April 1949, in World Health Organization, Basic Documents (WHO 48th ed 2014) 41.

Burci and Vignes, above n 2, 59-61.
} 
considerable body of policy and scholarly reviews focusing critically on the constitutional and operational role of the WHO Secretariat as custodian of the IHR (2005). ${ }^{28}$ Adam Kamrad Scott's contribution to this forum inscribes itself in this current of critical scholarship. Kamrad-Scott, an international relations scholar who worked in the IHR secretariat and therefore has first-hand experience of the professional and institutional challenges facing the organization, argues inter alia that the constitutional responsibility of the secretariat towards the effective implementation of a legal instrument of seminal importance for the integrity of its mandate militates in favour of more aggressive monitoring of national health measures that arguably breach IHR (2005) obligations. This remark challenges WHO's institutional culture, which has traditionally been non-confrontational and deferential towards member states in the name of the pursuit of shared health goals.

From another perspective, participation in WHO's governance has been characterized since its inception by the tensions between its intergovernmental nature, the strong universalist ethos of health and the active role historically played by non-state actors such as philanthropic foundations. ${ }^{29}$ The Constitution unsurprisingly mentions cooperation with the UN, other international organizations and non-governmental organizations, and those provisions form the basis for their participation in the work of WHO's governing bodies. ${ }^{30}$ However, it also provides for participation by non-self-governing territories in the form of associate membership. ${ }^{31}$ While this arrangement has become an historical relic, it played a larger role in the early phases of WHO's life and allowed its secretariat to engage directly with the health administrations of territories and build their capacities as part of the decolonization process. Steven Solomon and Claudia Nannini (whose contribution will be published

28 The main official assessment of WHO's performance in the Ebola crisis is Report of the Review Committee on the Role of the International Health Regulations (2005) in the Ebola Outbreak Response, WHO Doc A/69/21 (13 May 2016). Among scholarly reviews, the most comprehensive is Suerie Moon et al, 'Will Ebola Change the Game? Ten Essential Reforms before the Next Pandemic. The Report of the Harvard-LSHTM Independent Panel on the Global Response to Ebola' (2015) 386 The Lancet 2204.

29 On the deep global influence of the Rockefeller Foundation, see Packard, above n 9. The Bill and Melinda Gates Foundation seems to have taken over the mantle previously worn by the Rockefeller Foundation, raising similar concerns. See Anne-Emmanuelle Birn, 'Philanthrocapitalism, past and present: The Rockefeller Foundation, the Gates Foundation, and the setting(s) of the international/global health agenda' (2014) 12(1) Hypothesis 6; Lawrence O Gostin, Global Health Law (Harvard University Press, 2014) 162. WHO Constitution, above n 11, Articles 69-71. Ibid, Article 8. 
in the next issue of this journal due to unavoidable technical reasons) address the question of participation in WHO's governance by focusing on the tension between the intergovernmental nature of the organization and the need to accommodate the participation of a growing range of actors increasingly involved in global health governance. Solomon and Nannini are currently serving in WHO's Legal Office and thus able to provide insights on the development of practices that partly rely on the acquiescence of member states to the exercise by the Director-General of significant discretionary authority. Given the absence of formal approval by the governing bodies for some forms of participation as explained in Solomon and Nannini's article, it would be difficult to appreciate such governance innovations if not from inside the secretariat. Of particular interest from this perspective, therefore, is the decision by subsequent Directors-General to invite under their own authority a range of "observers" not fitting in the customary binary intergovernmental/non-governmental divide but playing a significant role in global health. ${ }^{32}$ Such authority relies on the lack of challenges by member states as the basis for granting a standing right of participation to the entities concerned and to legitimize the authority itself. While most invitations have been addressed to unproblematic institutions such as the Order of Malta and the International Committee of the Red Cross, the independent exercise of this authority by the Director-General has notably been used to manage delicate political situations such as inviting Chinese Taipei to participate in a few sessions of the Health Assembly.

Even though Solomon and Nannini focus on participation in WHO's governing bodies, participation should be understood in much broader terms that would warrant more scholarly attention. WHO's limited resources have led it to largely rely on both individual experts as well as collaborating public and private institutions for carrying out its normative and operational functions. ${ }^{33}$ This, in turn, has mainstreamed and validated an approach to normative work in good part structured along elaborate processes managed by the secretariat with the decisive contribution of experts serving in their personal capacity. This is particularly evident for the considerable number of guidelines or similar normative documents issued by the secretariat rather than forming the object of political negotiations within the governing bodies. While this approach is defended as depoliticizing normative products that are instead based on objective scientific and public health evidence and respond to real health needs, it has shifted power towards the secretariat and raises questions about the power of expertise, the legitimacy of this exercise of authority and

$32 \quad$ Burci and Vignes, above $\mathrm{n} 2,36-37$.

33 Ibid $146-15^{2}$. 
the interests represented at least indirectly by the experts relied upon by the secretariat. ${ }^{34}$ The two remaining contributions to this forum, while dealing with different aspects of WHO, raise a common methodological theme: the need to rethink critically the analytical tools required to better understand the essence of contemporary international organizations and how emblematic they are for broader global governance issues.

In this connection, Jan Klabbers questions how international lawyers address the normative powers of international organizations, with specific regard to WHO as a primary example of an organization that has hardly exercised its (hard) law-making powers but that nonetheless is perceived as an important and successful normative organization. As mentioned above, WHO has adopted just a few legally binding instruments in the course of its life. At the same time, it has produced a broad range of non-binding instruments with a clear normative intent and performed other activities with a considerable impact on the behavior of states and other public and private actors. ${ }^{35}$ Some of these instruments are adopted by the Health Assembly, but others are issued by the secretariat as mentioned above and yet other instances of normative authority are more diffuse and not formalized in some kind of legal shape. An extreme example is represented by the famous travel advisories posted on WHO's web site during the 2003 SARS outbreak. ${ }^{36}$ Klabbers argues that, rather than trying to shoehorn these functions into an ill-defined notion of "soft law" to make them fit into traditional legal categories, they should be reframed as exercise of epistemic authority disconnected from the formalities of lawmaking and grounded in science, expertise, the mission of the organization and its technical credibility. This analytical framework can be applied to other international organizations; it should enable legal scholars to construe power and authority in a holistic manner and to extend that analysis away from states as principals of international organizations to other actors such as notably executive heads, secretariats and expert bodies. Klabbers' approach arguably moves along similar lines of inquiry as other recent scholarly trends that have conceptualized contemporary forms of power and governance, e.g. the global

34 WHO guidelines: development and governance, WHO Doc EB137/35 (20 May 2015); Executive Board, 137th sess, first mtg, Summary records, EB137/2015/REC/1 35-40. See also Ole Jacob Sending, The Politics of Expertise: Competing for Authority in Global Governance (University of Michigan Press, 2017).

35 Burci and Vignes, above n 2, 141-155.

36 World Health Organization, 'WHO extends its SARS-related travel advice to Beijing and Shanxi province in China and to Toronto, Canada' (23 April 2003) <https://www.who.int/ mediacentre/news/notes/2003/np7/en/>. 
administrative law project ${ }^{37}$ and scholarship on the informalization of international law-making. ${ }^{38}$

Kristina Daugirdas and Gian Luca Burci apply an analytical approach to the financing of WHO which, as in Klabbers' case, questions some of the assumptions from the prevailing scholarship in looking at a phenomenon that has become dominant in the funding of institutionalized multilateral cooperation. The original design of international organizations, premised on the collective responsibility of member states to fund through assessed contributions an agent exercising functions in the collective interest of their principals, has considerably changed in practice. Since the early days of the UN system, voluntary contributions have entered the picture and constantly gained importance. Voluntary contributions, often earmarked for funding the donors' priority projects and increasingly coming from non-state actors rather than governments, have raised the concern of international relations scholars who highlight their negative implications and distorting effects for the multilateral project embodied by international organizations. ${ }^{39}$ Curiously, international lawyers have shown little interest in the legal implications of this trend and focused their attention on the different problem of unilateral withholding of assessed contributions. ${ }^{40}$ Daugirdas and Burci have chosen WHO as a case study from a legal perspective, in particular given its extreme dependence on voluntary contributions and its functions as a normative and policy-setting organization rather than a development or operational programme. However, unlike previous scholarship, they have approached it without preconceived conceptual viewpoints and tried to assess, including empirically through interviews with responsible WHO officials, how WHO has adapted to a challenging funding environment while largely remaining within the parameters of multilateralism. Their findings defy to a certain extent the assumptions of international relations scholars and point to the compatibility between multilateral governance processes taking place within the constitutional governance of an international organization on the one hand; and on the other hand a changing vision of the implementation of the constitutional mandate of the same organization, where the

37 Seminal is Benedict Kingsbury, Nico Krisch and Richard B Stewart, "The Emergence of Global Administrative Law' (2005) 68(3) Law \& Contemporary Problems 15.

38 Joost Pauwelyn, Ramses A Wessel and Jan Wouters (eds), Informal International Lawmaking (Oxford University Press, 2012).

39 Erin R Graham, 'Follow the Money: How Trends in Financing Are Changing Governance at International Organizations' (2017) 8 Global Policy 15.

$40 \quad$ Nigel D White, The law of international organisations (Manchester University Press, 3rd ed, 2017) 70. 
latter acts more and more as a proxy for the implementation of the policies of individual donors.

\section{Conclusions: Main Lessons and Areas for Research}

The four contributions to this forum present some similarities as well as tensions that point to larger issues in the governance of international organizations. Kamrad Scott's and Klabbers' articles focus on the normative output of WHO and aim at explaining (and in Kamrad Scott's case also at strengthening)its effectiveness and legitimacy (or lack thereof). Kamrad Scott focuses on WHO's corporate culture and weak institutional support for the IHR (2005) that decrease the meaningfulness of their very nature as a legally binding instrument; Klabbers, in contrast, shows how the empirical effectiveness and impact of many WHO activities (going beyond more "typical" normative functions and extending to things like training, statistics and indicators) do not need a legal framework for their justification but can be conceptualized on a different basis, as exercises of epistemic authority. These different but complementary arguments raise questions that resonate with both legal and international relations scholarship on legalization of global governance and the relevance of differentiating between "hard" and "soft" law and of theorizing on that basis. ${ }^{41}$ Klabbers' approach, in particular, deserves more attention from international lawyers and can open interesting perspective for interdisciplinary research into the activities of "technical" international organizations and how to understand their impact on a broad range of public and private actors. It also expands the role of the secretariats of international organizations as normative and "epistemic" actors in their own right rather than just supporting the intergovernmental processes of their respective institutions.

Daugirdas and Burci, and Solomon and Nannini, focus instead on the main "inputs" to the work of international organizations, namely, financial resources as well as participation in their decision-making processes. A point in common in their contributions is the "complexification" and blurring of the governance of international organizations that question the traditional paradigm of the supremacy of member states. From the perspective of WHO's financing, the

41 Seminal is Kenneth Abbott and Duncan Snidal, 'Hard and Soft Law in International Governance' (2000) 54(3) International Organisation 421. See also Gregory Shaffer and Mark A Pollack, 'Hard and Soft Law' in Jeffrey L Dunoff and Mark A Pollack (eds), Interdisciplinary Perspectives on International Law and International Relations (Cambridge University Press, 2013) 197. 
"Gates Foundation" phenomenon raises important questions about the implications of private funding of international public functions, especially when the level of funding rivals that of the most powerful states. Daugirdas and Burci's analysis show on the one hand how the most important private donors are treated by the WHO secretariat just like member states from the perspective of strategic planning and accountability. On the other hand, one of the findings of their empirical research is that institutional safeguards on private funding to preserve the integrity of the organization from conflicts of interest or corporate capture have not decreased or undermined that source of funding. Solomon and Nannini show how WHO's governance has accommodated a diverse range of actors based on their actual role and influence in global health and how even the public is seen as a participant from the perspective of outreach and advocacy on WHO's work. While these developments and innovations do not undermine the intergovernmental nature of WHO, they expand the role of other actors, the space afforded to them to assert their interests and agendas and their actual influence on WHO's decisions and functions. While this phenomenon is certainly not exclusive of WHO, the "technical" nature of the organization and the expertise contributed by non-state actors has probably facilitated it and has allowed the Director-General to create a category of "observers" relying on the acquiescence of member states to their participation. The latter development would be unthinkable in more "political" organizations, starting with the UN.

In conclusion, it would be interesting to extend these directions of research to other "technical" organizations (albeit with due regard to their structural differences), both to cast a fresh look on the theoretical bases of their functions as well as to test whether we are witnessing their transformation in practice from public agencies underpinned by functionalism and principal-agent theories to increasingly multi-stakeholder arrangements. 